\title{
Deposition of $\operatorname{In}_{2} S_{3}$ on $\mathrm{Cu}(\mathrm{In}, \mathrm{Ga})(\mathrm{S}, \mathrm{Se})_{2}$ thin film solar cell absorbers by spray ion layer gas reaction: Evidence of strong interfacial diffusion
}

\author{
M. Bära) \\ Department of Chemistry, University of Nevada, Las Vegas, 4505 Maryland Parkway, Las Vegas, Nevada \\ 89154 and Solarenergieforschung (SE2), Hahn-Meitner-Institut Berlin, Glienicker Strasse 100, \\ D-14109 Berlin, Germany
}

\author{
N. Allsop, I. Lauermann, and Ch.-H. Fischer ${ }^{\text {b) }}$ \\ Solarenergieforschung (SE2), Hahn-Meitner-Institut Berlin, Glienicker Strasse 100, D-14109 Berlin, \\ Germany
}

(Received 19 January 2007; accepted 23 February 2007; published online 29 March 2007)

\begin{abstract}
Recently, Cd-free $\mathrm{Cu}(\mathrm{In}, \mathrm{Ga})(\mathrm{S}, \mathrm{Se})_{2}$-based "CIGSSe" thin film solar cells with a nominal $\mathrm{In}_{2} \mathrm{~S}_{3}$ buffer layer deposited by the spray ion layer gas reaction technique resulted in photovoltaic performances comparable to that of CdS buffered references. In the past it was argued that diffusion processes across the $\mathrm{In}_{2} \mathrm{~S}_{3} /$ CIGSSe interface play a significant role for the device quality. Investigating the interface formation by using $\mathrm{x}$-ray photoelectron spectroscopy, the authors were able to confirm a strong interfacial diffusion involving $\mathrm{Cu}$ and $\mathrm{Na}$ from the CIGSSe. (C) 2007 American Institute of Physics. [DOI: 10.1063/1.2717534]
\end{abstract}

$\mathrm{Cu}\left(\operatorname{In}_{(1-X)} \mathrm{Ga}_{X}\right)\left(\mathrm{S}_{\mathrm{Y}} \mathrm{Se}_{(1-Y)}\right)_{2}$ ("CIGSSe") thin film solar cells promise to be the next generation of photovoltaic cells, superseding the more expensive current state-ofthe-art Si-based solar cell technology. Corresponding $n^{+}-\mathrm{ZnO} / i$-ZnO/CdS/CIGSSe/Mo/glass devices have already reached power conversion efficiencies close to $20 \%{ }^{1}$ However, because of economic and ecological reasons there is a strong impetus to replace not only the $\mathrm{CdS}$ layer by a nontoxic, more transparent alternative buffer but also the conventionally used chemical bath deposition (CBD) by a technique which is capable of in-line processing. $\operatorname{In}_{2} \mathrm{~S}_{3}$ layers deposited by physical vapor deposition ${ }^{2}$ (PVD), sputtering, ${ }^{3}$ or atomic layer deposition ${ }^{4,5}$ (ALD) are among the promising alternatives. Recently, nominal $\mathrm{In}_{2} \mathrm{~S}_{3}$ buffers were also prepared by the spray ion layer gas reaction ${ }^{6}$ (Spray-ILGAR). The resulting CIGSSe-based solar cells yield comparable efficiencies $^{6}$ and stabilities ${ }^{7}$ as corresponding CBD-CdS buffered references.

Despite the fact that for ALD- $\operatorname{In}_{2} \mathrm{~S}_{3}$ the highest growth rate is reported for process temperatures between 160 and $180{ }^{\circ} \mathrm{C},{ }^{8}$ different optimization experiments ${ }^{4,9}$ show that for the best photovoltaic performance it is necessary to prepare the ALD- $\mathrm{In}_{2} \mathrm{~S}_{3}$ buffer at much higher temperatures $\left(210-220{ }^{\circ} \mathrm{C}\right)$. This might be an indication that the thermal input during interface formation between buffer and absorber plays an important role for the performance of respective solar cells. In fact, based on x-ray photoelectron ${ }^{4,10}$ (XPS), secondary ion mass, 3,9 or sputtered neutral mass spectroscopy ${ }^{9}$ depth profiles, several groups have found that there is a thermally driven diffusion of copper and also of sodium (stemming from the soda-lime glass) from the CIGSSe substrate into the $\mathrm{In}_{2} \mathrm{~S}_{3}$ buffer layer. This was also recently confirmed by microstructural studies of the $\mathrm{In}_{2} \mathrm{~S}_{3} /$ chalcopyrite interface by transmission electron micrographs and related energy dispersive $\mathrm{X}$-ray analysis. ${ }^{11}$ Similar

\footnotetext{
${ }^{\text {a) }}$ Author to whom correspondence should be addressed; FAX: 1-702-8954072; electronic mail: baerm2@unlv.nevada.edu

b) Also at: Freie Universität Berlin, 14195 Berlin, Germany.
}

diffusion processes were also reported for PVD- $\operatorname{In}_{2} \mathrm{~S}_{3}$. ${ }^{2,12}$ The optimal process temperature for the preparation of Spray-ILGAR $\operatorname{In}_{2} \mathrm{~S}_{3}$ buffers with respect to the performance of corresponding solar cells is comparable ${ }^{6}\left(200-250{ }^{\circ} \mathrm{C}\right)$ to that for optimal ALD- $\operatorname{In}_{2} \mathrm{~S}_{3}$ buffers. Hence, in this letter we will investigate whether across the Spray-ILGAR $\mathrm{In}_{2} \mathrm{~S}_{3} /$ CIGSSe ALD-In $\mathrm{S}_{3}$ interface such diffusion processes also take place. However, in contrast to the destructive sputter depth profiling experiments mentioned above, whose results critically depend on the exact knowledge of the sputter and ionization cross sections, respectively, we use a different approach. The Spray-ILGAR $\mathrm{In}_{2} \mathrm{~S}_{3} / \mathrm{CIGSSe}$ interface formation is investigated by monitoring the surface composition of a set of CIGSSe samples with differently thick nominal $\operatorname{In}_{2} \mathrm{~S}_{3}$ cover layers with XPS and thus is not necessarily the equivalent to a depth profile.

All experiments were based on industrial-grade CIGSSe/ Mo/glass absorber substrates from the pilot line of Shell Solar GmbH (now AVANCIS GmbH \& Co. KG). The CIGSSe is formed by rapid thermal annealing of stacked elemental layers on Mo-coated soda-lime glass in a sulfur containing atmosphere. ${ }^{13}$ For the preparation of the nominal $\mathrm{In}_{2} \mathrm{~S}_{3}$ layers, we used the Spray-ILGAR technique, ${ }^{6,14}$ where a precursor solution is sprayed onto the heated absorber substrates followed by conversion of the solid film to a chalcogenide by a reactive gas. In the present study, the spray solution used is $\mathrm{InCl}_{3}$ dissolved in ethanol and the reactive gas is $\mathrm{H}_{2} \mathrm{~S}$. A more detailed description can be found elsewhere. ${ }^{6,7,14} \mathrm{Be}$ cause of the cyclical nature of the Spray-ILGAR process, the thickness of the buffer layer can simply be adjusted by varying the number of spray cycles. A set of samples where this number has been varied between 0 (bare, uncovered CIGSSe absorber), 1, 2, 3, 4, and 6 was investigated. The process temperature for all samples was $250{ }^{\circ} \mathrm{C}$, for which the growth rate was determined to be $\sim 3.3 \mathrm{~nm} /$ cycle. ${ }^{6}$ After preparation, the $\left(1 / 2 \times 1 \mathrm{in}^{2}\right)$ samples were sealed in a polyethylene bag filled with $\mathrm{N}_{2}$. The sample transfer was performed as quickly as possible in order to limit the exposure time to ambient air. Then, the samples were transferred into 


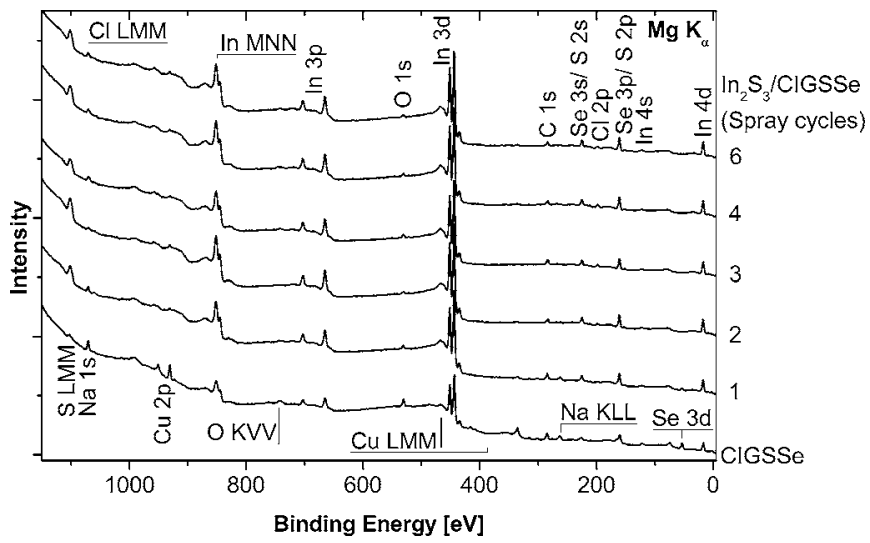

FIG. 1. XPS survey spectra of differently thick $\operatorname{In}_{2} \mathrm{~S}_{3}$ layers deposited on CIGSSe absorbers by a varying number of spray cycles.

the analysis chamber of a combined ultrahigh vacuum preparation and spectroscopy system ("CISSY," see Ref. ${ }^{15}$ for more details) at a base pressure of $<1 \times 10^{-9}$ mbar via an attached $\mathrm{N}_{2}$ filled glovebox. The samples were characterized by XPS using $\mathrm{Mg} K \alpha(1253.6 \mathrm{eV})$ and $\mathrm{Al} K \alpha(1486.6 \mathrm{eV})$ excitations and a CLAM4 electron spectrometer from Thermo VG Scientific (calibrated according to Ref. 16).

Figure 1 shows the XPS survey spectra of the investigated samples. For the uncovered CIGSSe absorber the spectrum is dominated by features, which can be ascribed to $\mathrm{Cu}$, In, S, and Se. Interestingly, no Ga-related XPS or Auger peaks can be observed, confirming the earlier reported accumulation of $\mathrm{Ga}$ exclusively at the Mo back contact. ${ }^{17}$ As expected, distinct spectral features attributed to $\mathrm{Na}$ can also be identified. The small features attributed to $\mathrm{O}$ and $\mathrm{C}$ (which are ascribed to a minor surface contamination layer) are indicative for a rather clean sample surface. Thus, the impact of the signal attenuation induced by this surface contamination layer, which is more pronounced for low kinetic energy photoemission lines (e.g., $\mathrm{Cu} 2 p$ ), on the comparison of different photoemission lines is considered to be minimal. With increasing number of spray cycles and thus increasing $\operatorname{In}_{2} \mathrm{~S}_{3}$ layer thickness, the XPS and Auger signals ascribed to $S$ and In become more intense. Close inspection of the survey spectra reveals a small but distinct additional feature attributable to the most prominent $\mathrm{Cl}$ photoemission line $(\mathrm{Cl} 2 p$ at a binding energy $E_{B}$ of $199 \mathrm{eV}$ ), which increases in intensity with the number of spray cycles. This might be due to an incomplete conversion of the precursor to the sulfide, which has been previously studied. ${ }^{14}$ The detail spectra in Fig. 2(a) reveal that the intensity of the CIGSSe related $\mathrm{Na} 1 s, \mathrm{Cu} 2 p$

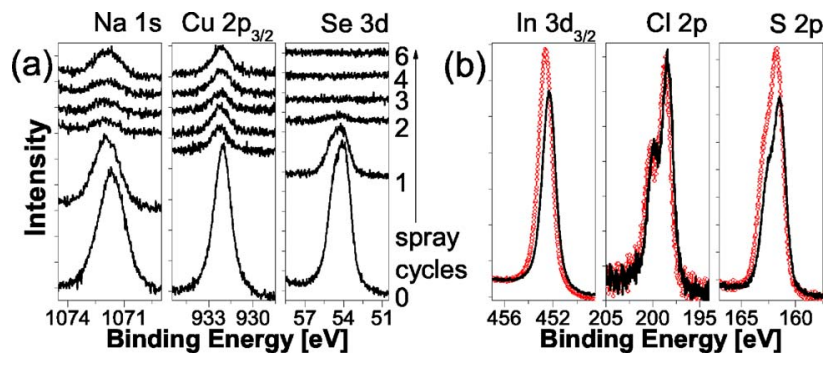

FIG. 2. (Color online) (a). Na $1 s, \mathrm{Cu} 2 p_{3 / 2}$, and Se $3 d$ XPS detail spectra of the investigated sample series. (b). In $3 d_{3 / 2}, \mathrm{Cl} 2 p$, and S $2 p$ XPS detail spectra of a four-cycle $\operatorname{In}_{2} \mathrm{~S}_{3}$ layer deposited on CIGSSe (black line) and Mo

samples' surface composition is shown for each spray cycle
(red open circles). and Se $3 d$ photoemission lines decreases, but despite the largest photoelectrons' inelastic mean free path only the Se $3 d$ signal vanishes after three spray cycles. Assuming that the Se $3 d$ signal represents the CIGSSe surface (note that the $\mathrm{S}$ :Se ratio is not altered significantly by applying $\mathrm{H}_{2} \mathrm{~S}$ at $250{ }^{\circ} \mathrm{C}$ to the bare CIGSSe), this finding points to an outdiffusion of $\mathrm{Na}$ and $\mathrm{Cu}$ from the CIGSSe absorber during the ILGAR process and their subsequent incorporation into the $\mathrm{In}_{2} \mathrm{~S}_{3}$ layer. However, for the sake of clarity this material is still referred to as $\operatorname{In}_{2} \mathrm{~S}_{3}$ in this letter. The disappearance of the Se $3 d$ photoemission line on the other hand is indicative of a complete coverage of the CIGSSe by the three cycle $\mathrm{In}_{2} \mathrm{~S}_{3}$ layer with a minimum thickness which corresponds to the XPS information depth (for Se $3 d$ excited with $\mathrm{Mg} K \alpha$ this is approximately $7.5 \mathrm{~nm}$ ). Note that all shown detail spectra were recorded using $\mathrm{Mg} K \alpha$ excitation except that of the Na $1 s$ photoemission line in Fig. 2(a). Here, $\mathrm{Al} K \alpha$ excitation was used in order to prevent the overlap with the $\mathrm{Cl}$ $L M M$ Auger peak (see Fig. 1). In addition to the $\mathrm{In}_{2} \mathrm{~S}_{3} /$ CIGSSe test structures an $\operatorname{In}_{2} \mathrm{~S}_{3}$ reference sample was prepared on a Mo/glass substrate using four spray cycles. The respective In $3 d_{3 / 2}, \mathrm{Cl} 2 p$, and $\mathrm{S} 2 p$ detail spectra are compared to those of the corresponding $\mathrm{In}_{2} \mathrm{~S}_{3} / \mathrm{CIGSSe}$ sample in Fig. 2(b). While the intensity of the $\mathrm{Cl} 2 p$ spectra is independent of the substrate, indicating a comparable layer thickness, we find increased In $3 d_{3 / 2}$ and $\mathrm{S} 2 p$ intensities for the $\mathrm{In}_{2} \mathrm{~S}_{3} /$ Mo sample. The shift of all photoemission lines of the Mo sample to higher $\mathrm{E}_{\mathrm{B}}$ by approximately $0.3 \mathrm{eV}$ can be explained by a different interface induced band bending caused by the deposition of $\operatorname{In}_{2} \mathrm{~S}_{3}$ on either CIGSSe or Mo. The increased In- and S-related XPS intensities of the $\mathrm{In}_{2} \mathrm{~S}_{3} /$ Mo sample confirms the interpretation from above that the $\mathrm{In}_{2} \mathrm{~S}_{3}$ layer deposited on CIGSSe is not exclusively composed of In and $S$ but rather contains additional ingredients on cation as well as anion sites. In order to shed light on the suspected diffusion process, the XPS data were quantified. As generally known the photoemission signal intensity is directly proportional to the elemental concentration $c$, the ionization cross section $\sigma$, the inelastic mean free path $\lambda$, and the transmission of the electron analyzer $T$. Thus in order to obtain $c$, the intensity of the XPS line was determined by fitting the photoemission peak using a Voigt function and a linear background. Note that doublets were fitted with two Voigt functions with intensity ratios set according to their spin-orbit splitting. Then we followed two approaches to estimate $c$. First we assumed that for photoelectrons with a kinetic energy, $E_{K}>30 \mathrm{eV} \lambda \propto E_{K}^{1 / 2}$ and $T \propto E_{K}^{-1 / 2}$, and hence we corrected the peak intensities only for $\sigma$ (taken from Ref. 18) to determine $c$. In our second approach, we additionally considered $\lambda$ and $T$. $\lambda$ was calculated by the TPP2M formula ${ }^{19}$ for a pure $\mathrm{In}_{2} \mathrm{~S}_{3}$ layer using the QUASES code written by Tougaard. ${ }^{20} T$ of the used electron analyzer was determined by measuring the $\mathrm{Au} 4 f$ photoemission line at a (in terms of excitation energy) tuneable light source. In order to account for the uncertainty in these quantification approaches, in the following always their average together with the standard deviation from the mean value is given. Note that the resulting very defensively designed error margins certainly also include possible deviations from the calculated composition due to differently pronounced attenuation of the photoemission lines by the surface contamination layer (see above). The resulting picture is shown in Fig. 3(a), where the samples' surface composition is shown for each spray cycle. AIP license or copyright, see http://apl.aip.org/apl/copyright.jsp 


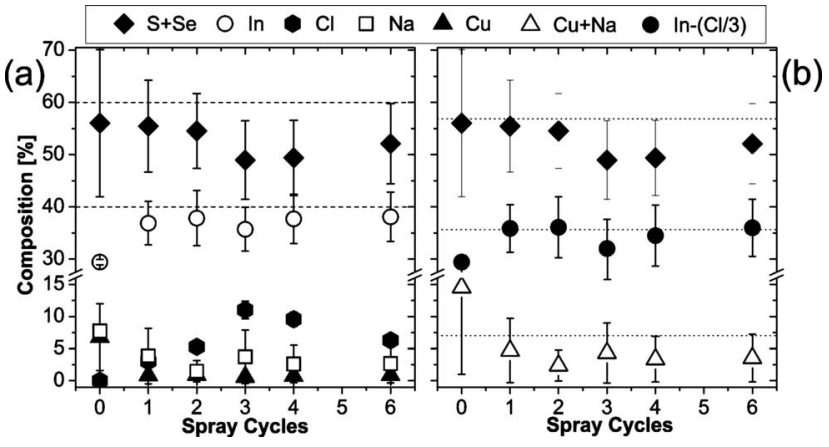

FIG. 3. Surface composition of the investigated sample series as determined from the collected XPS data. The dashed lines in (a) indicate the S and In content of a pure $\operatorname{In}_{2} \mathrm{~S}_{3}$ layer and the dotted lines in (b) represent the 1:5:8 composition of a possible $\left(\mathrm{Cu}_{1-X} \mathrm{Na}_{X}\right) \mathrm{In}_{5} \mathrm{~S}_{8}$ phase.

Note that according to the $\mathrm{CuIn}(\mathrm{S}, \mathrm{Se})_{2}$ composition of the absorber's surface the presented surface content of $\mathrm{S}$ and $\mathrm{Se}$ is combined. However, keep in mind that $[\mathrm{Se}]=0$ after three spray cycles. Despite the partially extensive error bars, some conclusions can nevertheless be drawn from Fig. 3(a). The surface of the CIGSSe (" 0 spray cycles") is $\mathrm{Cu}$ poor. In addition, it can be observed that the $\mathrm{Cl}$ content increases with the number of spray cycles and reaches a maximum of $(11 \pm 2) \%$ at three cycles. This can be understood by the thicker growing buffer layer, causing the $\mathrm{Cl}$ content to increase until the layer thickness is in the range of the XPS information depth. Furthermore, as already expected from Fig. 2(a), the amount of $\mathrm{Cu}$ and $\mathrm{Na}$ decreases with increasing number of spray cycles, levels off after three cycles, and is still significant after six cycles $([\mathrm{Cu}]=(1 \pm 1) \%$ ! and $[\mathrm{Na}]$ $=(3 \pm 3) \%)$. A further indication of additional buffer constituents other than In and $\mathrm{S}$ is found in the $\mathrm{S}(+\mathrm{Se})$ content of the samples prepared by three cycles or more. It does not comply (even within the defensively designed error bars) with the assumption of the formation of a pure $\operatorname{In}_{2} \mathrm{~S}_{3}$ for which the respective $\mathrm{S}$ content is indicated by the upper dashed line in Fig. 3(a). In order to evaluate whether our data support the formation of a $\left(\mathrm{Cu}_{1-X} \mathrm{Na}_{X}\right) \mathrm{In}_{5} \mathrm{~S}_{8}$ phase as suggested by Barreau et al. ${ }^{21}$ for ALD- and PVD- $\operatorname{In}_{2} \mathrm{~S}_{3}$ deposited on CIGSSe absorbers, the constituents of the Spray-ILGAR buffer are combined, respectively, assuming a mixed composition of $\left(\mathrm{Cu}_{1-X} \mathrm{Na}_{X}\right) \operatorname{In}_{5} \mathrm{~S}_{8}$ and remainders of unconverted precursor $\left(\mathrm{InCl}_{3}\right)$. Thus, $\mathrm{Cu}+\mathrm{Na}, \mathrm{S}(+\mathrm{Se})$, and (in order to correct the In for the $\mathrm{Cl}$ content) $\mathrm{In}-(\mathrm{Cl} / 3)$ amounts are presented in Fig. 3(b). Based on the (within the error bars) good agreement of the measured composition for samples deposited by three or more spray cycles with the indicated 1:5:8 composition [dotted lines in Fig. 3(b)], one could speculate that indeed a $\left(\mathrm{Cu}_{1-X} \mathrm{Na}_{X}\right) \operatorname{In}_{5} \mathrm{~S}_{8}$ phase is formed. However, a mixture of different phases or even the formation of $\mathrm{NaCl}$ (favored by the affinity of $\mathrm{Na}$ to $\mathrm{Cl}$ ) cannot be excluded.
In summary, we conclude that similar to the ALD and PVD depositions of $\mathrm{In}_{2} \mathrm{~S}_{3}$ on CIGSSe also during the SprayILGAR process distinct interfacial diffusion processes take place, which in particular involve $\mathrm{Cu}$ and $\mathrm{Na}$. In addition, we find $\mathrm{Cl}$ from unconverted precursor in the deposited nominal $\mathrm{In}_{2} \mathrm{~S}_{3}$. Further work is needed to shed more light on the actual buffer composition, especially concerning the role of $\mathrm{Cl}$.

The authors acknowledge Shell Solar GmbH for providing the CIGSSe absorbers and the CISSY group for their help. One of the authors (M.B.) is grateful to the DFG for partial sponsorship within the Emmy-Noether Programm.

${ }^{1}$ M. A. Green, K. Emery, D. L. King, Y. Hishikawa, and W. Warta, Prog. Photovoltaics 15, 35 (2007).

${ }^{2}$ N. Barreau, J. C. Bernede, S. Marsillac, C. Amory, and W. N. Shafarman, Thin Solid Films 431-432, 326 (2003).

${ }^{3}$ D. Hariskos, R. Menner, S. Spiering, A. Eicke, M. Powalla, K. Ellmer, M. Oertel, and B. Dimmler, Proceedings of the 19th European Photovoltaic Solar Energy Conference, Paris, France, 7-11 June 2004 (WIP, Munich, 2004), p. 1894

${ }^{4}$ N. Naghavi, S. Spiering, M. Powalla, B. Canava, and D. Lincot, Prog. Photovoltaics 11, 437 (2003).

${ }^{5}$ N. Naghavi, R. Henriquez, V. Laptev, and D. Lincot, Appl. Surf. Sci. 222, 65 (2004).

${ }^{6}$ N. A. Allsop, A. Schönmann, H.-J. Muffler, M. Bär, M. C. Lux-Steiner, and Ch.-H. Fischer, Prog. Photovoltaics 13, 607 (2005).

${ }^{7}$ N. A. Allsop, A. Hänsel, S. Visbeck, T. P. Niesen, M. C. Lux-Steiner, and Ch.-H. Fischer, Thin Solid Films 511-512, 55 (2006).

${ }^{8}$ J. Sterner, J. Malmström, and L. Stolt, Prog. Photovoltaics 13, 179 (2005).

${ }^{9}$ S. Spiering, A. Eicke, D. Hariskos, M. Powalla, N. Naghavi, and D. Lincot, Thin Solid Films 451-452, 562 (2004).

${ }^{10}$ N. Naghavi, J.-F. Guillemoles, D. Lincot, B. Canava, A. Etcheberry, S. Taunier, S. Spiering, M. Powalla, M. Lamirand, and L. Legras, Proceedings of the 19th European Photovoltaic Solar Energy Conference, Paris, France, 7-11 June 2004 (WIP, Munich, 2004), p. 1733.

${ }^{11}$ D. Abou-Ras, D. Rudmann, G. Kostorz, S. Spiering, M. Powalla, and A. N. Tiwari, J. Appl. Phys. 97, 084908 (2005); D. Abou-Ras, G. Kostorz, A. Strom, H.-W. Schock, and A. N. Tiwari, ibid. 98, 123512 (2005).

${ }^{12}$ S. Gall, N. Barreau, S. Harel, J. C. Bernéde, and J. Kessler, Thin Solid Films 480-481, 138 (2005).

${ }^{13}$ J. Palm, V. Probst, W. Stetter, and R. Toelle, Mater. Res. Soc. Symp. Proc. 763, B6.8.1 (2003), and references therein.

${ }^{14}$ N. A. Allsop, A. Schönmann, A. Belaidi, H.-J. Muffler, B. Mertesacker, W. Bohne, E. Strub, J. Röhrich, M. C. Lux-Steiner, and Ch.-H. Fischer, Thin Solid Films 513, 52 (2006).

${ }^{15}$ I. Lauermann, M. Bär, A. Ennaoui, U. Fiedeler, Ch-H. Fischer, A. Grimm, I. Kötschau, M. Ch. Lux-Steiner, J. Reichardt, B. R. Sankapal, S. Siebentritt, S. Sokoll, L. Weinhardt, O. Fuchs, C. Heske, C. Jung, W. Gudat, F. Karg, and T. P. Niesen, Mater. Res. Soc. Symp. Proc. 763, B4.5.1 (2003).

${ }^{16}$ C. D. Wagner, W. M. Riggs, L. E. Davis, and J. F. Moulder, Handbook of $X$-Ray Photoelectron Spectroscopy, edited by G. E. Moulder (PerkinElmer, Eden Prairie, 1979), p. 15.

${ }^{17}$ M. Bär, W. Bohne, J. Röhrich, E. Strub, S. Lindner, M. C. Lux-Steiner, Ch.-H. Fischer, T. P. Niesen, and F. Karg, J. Appl. Phys. 96, 3857 (2004).

${ }^{18}$ J. H. Scofield, J. Electron Spectrosc. Relat. Phenom. 8, 129 (1976).

${ }^{19}$ S. Tanuma, C. J. Powell, and D. R. Penn, Surf. Interface Anal. 21, 165 (1993).

${ }^{20}$ S. Tougaard, QUASES-IMFP-TPP2M code for the calculation of the inelastic electron mean free path, Version 2.2, http://www.quases.com/

${ }^{21}$ N. Barreau, C. Deudon, A. Lafond, S. Gall, and J. Kessler, Sol. Energy Mater. Sol. Cells 90, 1840 (2006). 